\title{
A physically based material model for the simulation of friction stir welding
}

\author{
Florian Panzer, Elizaveta Shishova, \\ Martin Werz, Stefan Weihe, Peter \\ Eberhard and Siegfried Schmauder, \\ Stuttgart, Germany
}

\author{
Article Information \\ Correspondence Address \\ Florian Panzer, M.SC. \\ Materialprüfungsanstalt (MPA) \\ Universität Stuttgart \\ Abteilung Fügetechnik und Additive Fertigung \\ Referat Fügeverfahren \\ Pfaffenwaldring 32 \\ D-70569 Stuttgart, Germany \\ E-mail: florian.panzer@mpa.uni-stuttgart.de
}

\section{Keywords}

material modeling, plasticity, friction stir welding, microstructural evolution, smoothed particle hydrodynamics
A physically based material model, taking into account the interdependence of material microstructure and yield strength, is presented for an Al 5182 series aluminum alloy for the simulation of friction stir welding using continuum mechanics approaches. A microstructure evolution equation considering dislocation density and grain size is used in conjunction with a description of yield stress. In order to fit experimental stress-strain curves, obtained from compression tests at various strain rates and temperatures, phenomenological relationships are developed for some of the model parameters. The material model is implemented in smoothed particle hydrodynamic research code as well as in the commercial finite element code Abaqus. Simulations for various strain rates and temperatures were performed and compared with experimental results as well as between the two discretization methods in order to verify the material model and the implementation. Simulations provide not only an accurate approximation of stress based on temperature, strain rate, and strain but also an improved insight into the microstructural evolution of the material.
Friction stir welding (FSW) is a solid state joining process invented in 1991 at the Welding Institute (TWI) [1] that is especially well suited for joining aluminum alloys [2]. A rotating tool consisting of pin and shoulder is pressed into the gap between two adjoining parts. The heat created from the friction between tool and material as well as in the material itself leads to a softening and plasticizing of the parts. The translational motion of the tool along the seam line together with the rotational motion creates the weld. Compared to fusion welding methods, the materials do not melt during friction stir welding, which results in very good joint qualities, especially for aluminum alloys. Additionally, it allows for the joining of dissimilar materials like steel and aluminum [3]. These circumstances make FSW a well suited joining technology for lightweight components.

In order to further understand, improve, and develop friction stir welding, simulations of the process are needed in addition to experimental analyses. Since the resulting joint strength of the weld, the occurrence of welding defects, and the height of process forces are all influenced by material behavior, appropriate constitutive equations considering all relevant effects have to be used. As the literature review further shows, most of the material constitutive equations used for continuum mechanics process simulations of FSW are purely phenomenological material models that provide a relationship for yield stress while taking into consideration strain, strain rate, and temperature. However, they do not consider the evolution of the microstructure of the material during the joining process. Models that provide insight into the microstructure are usually not intended for use in continuum mechanics simulations. A material model for FSW that bridges this gap is, to the knowledge of the authors, still missing.
While FSW has often been simulated using finite element or computational fluid dynamics approaches, smoothed particle hydrodynamics (SPH) simulations are scarce. SPH is a Lagrangian mesh-free discretization method [4] able to handle large deformations, discontinuities, and topology changes in simulations. Since FSW is a process with complex interactions, it provides a challenge as well as new opportunities to further improve SPH codes. Multiple interdependent physical phenomena have to be incorporated in order to yield an accurate representation of this joining process, including thermomechanical coupling, inelastic material behavior, friction contact, and heat generation. According to the literature review, several successful FSW simulations exist. One based on the microstructural material nature is however absent. The general characteristics of SPH, along with the ability to handle large deformations, allow 
straightforward implementation of such a model.

The aim of this work is, for the reasons mentioned above, the development of a physically based material model for aluminum applicable to friction stir welding continuum mechanics simulations, especially to smoothed particle hydrodynamics. The model describes the stress-strain behavior of the material at various temperatures and strain rates. The behavior of the material is calculated on the basis of microstructural properties, that is, dislocation density and grain size. An evolution equation for the microstructure is used. This modeling approach provides further means of validation. While continuum mechanical simulations of FSW are usually validated using force and temperature measurements, the new model can also be validated by comparing microsections of the welds with simulative results. The model is kept as simple as possible. This, in return, means that phenomenological relationships have to be applied in order to fit experimental data like stressstrain curves.

The model is developed as a first step for non-heat-treatable aluminum alloys. Therefore, the model does not have to include effects of precipitation which become important for heat-treatable alloys, e.g., 2000, 6000 and 7000 series aluminum alloys. The material model parameters are identified for the aluminum alloy EN AW 5182, a representative non-heat-treatable alloy used, for example, in automotive applications. The chemical composition of EN AW 5182 is shown in Table 1.

Parameter identification of the model is performed using results from compression tests at various strain rates and temperatures which were conducted at the Materials Testing Institute, University of Stuttgart (MPA). After parameter identification, the model was implemented as a VUHARD subroutine in Abaqus as well as in the SPH-code Pasimodo [5]. A model of the compression test was set up in both simulation codes, and the results were compared with the experimental outcomes as well as mutually.

\section{Literature review}

Much research has been done regarding the modeling of the friction stir welding pro- cess. Various methods, like finite elements (FE) [7-10], computational fluid dynamics (CFD) [11] or smoothed particle hydrodynamics (SPH) [12, 13], have been used to simulate FSW. While CFD and SPH simulations can cope with the large deformations that occur during the process, special finite element formulations have to be used. Methods employed by researchers are the arbitrary Lagrangian-Eulerian (ALE) approach [7] that allows for adaptive meshing or the coupled Eulerian-Lagrangian (CEL) approach [8-10] where a contact is used to couple Lagrangian and Eulerian material domains. A more extensive review of the numerical modeling of the friction stir welding process can, for example, be found in [14].

During friction stir welding, large strains, large strain rates as well as elevated temperatures occur [15] and therefore need to be considered in the material model of the simulation. A wide variety of material constitutive laws has been used by researchers as indicated in [15] or [16]. Examples are the Sellars and Tegart/Sheppard and Wright law, the Johnson-Cook plasticity law, the Hart model, or the Kocks and Mecking model. A comparison of results computed through varied constitutive laws for an Al 5083 alloy with finite elements [15] shows considerable variations in calculated stress, strains, strain rates, and temperatures. Calculations for an Al 6061 alloy with a CFD analysis and diverse constitutive laws [16] also show considerable variations in the results. This shows that care must be taken when selecting a material constitutive law for the simulation of FSW.

Frequently, the Johnson-Cook model [17] is used in continuum mechanic simulations of the FSW process, for example in $[8-10,18]$. One reason may be that it is already implemented and available in FEcodes like Abaqus or LS-DYNA. The model was developed originally to simulate ballistic problems. A major drawback of the Johnson-Cook model when looking at the simulation of friction stir welding is that it overpredicts the yield stress for large strains $[19,20]$, i. e., the flattening of the stress-strain curve due to dynamic recrystallization [21] is not taken into account. A modified Johnson-Cook material model is presented in [22]. The modifications aim to overcome the drawbacks of the original

\begin{tabular}{|c|c|c|c|c|c|c|c|}
\hline $\mathrm{Si}$ & $\mathrm{Fe}$ & $\mathrm{Cu}$ & $\mathrm{Mn}$ & $\mathrm{Mg}$ & $\mathrm{Cr}$ & $\mathrm{Zn}$ & $\mathrm{Ti}$ \\
\hline 0.2 & 0.35 & 0.15 & $0.2-0.5$ & $4.0-5.0$ & 0.1 & 0.25 & 0.1 \\
\hline
\end{tabular}

Table 1: Alloying elements of EN AW 5182 in wt. \% [6]

model. Additionally, microstructure describing variables are indirectly incorporated through a modified equation for the plastic strain. However, no indication is made regarding how well the calculated results correlate with experimental findings. In contrast to the Johnson-Cook model, the Sellars and Tegart/Sheppard and Wright constitutive law takes into account the flattening of the stress-strain curve. However, it contains no strain dependency at all.

For this reason, material models specific to an application in FSW process simulations have been developed, for example in [19] and [20]. In both works, constitutive equations expressing the yield stress depending on strain, strain rate, and temperature are presented. Both models provide a better fit for experimental data concerning aluminum than the Johnson-Cook model does.

The above mentioned material models, with the exception of [22], are purely phenomenological, i.e., the influence of the microstructure on the yield stress is not taken into account. Information about the microstructure can only be gained through post-processing. In [23], the FSW of an AZ31 Mg alloy is simulated via a continuum mechanical approach using the Sellars and Tegart/Sheppard and Wright constitutive model. In a subsequent step, a relationship between the Zener-Hollomon parameter and grain size, as presented in [24], is used to calculate the grain size in a weld. The grain size in turn is used to calculate the Vickers microhardness. A similar approach using a SPH simulation of the FSW of AZ31 Mg is used in [12]. In [25], another sequential approach is presented where temperature histories obtained from a thermo-mechanical simulation of $\mathrm{Al} 6111$ T4 are used in a subsequent step in a microstructural model to calculate the distribution of precipitates in the weld.

An insight into the microstructure of the materials is provided in physically based material models. A dislocation density evolution equation, as for example shown in [26] and [27], can be used to describe the development of the microstructure of the material with ongoing deformation.

A physically based model for the description of the flow stress of AISI 316L steel for a strain up to 0.6 and a large variety of temperatures and strain rates is presented in [28]. The flow stress is calculated based on evolution equations for dislocation density and vacancy concentration. The model is calibrated with results from compression tests and validated through additional tests 
displaying, for example, strain rate jumps. In [29], this material model is implemented into a particle finite element method software and used to simulate an orthogonal cutting process where the workpiece is discretized via particles and the tool is discretized via finite elements.

A microstructure-based model that calculates the strength and strain hardening with respect to precipitates for a friction stir welded Al 6005A-T6 alloy is presented in [30] and [31]. The model is part of a sequential modeling chain that aims to predict the properties of FSW joints. However, the model is not implemented in a continuum mechanics process simulation.

In [32], a model for $\mathrm{Al} 6061$ alloy is presented that takes into account the effects of precipitates on kinematic and isotropic hardening. The aim is to simulate the cyclic behavior of welded aluminum joints, i.e., the influence of temperature on the material and its microstructure is considered. The experimental and simulation results presented are for strains smaller than 0.01 , which is considerably lower than the strains that might be expected during friction stir welding [15]. Another microstructure based model for simulating the isotropic and kinematic hardening of an $\mathrm{Al} 7449$ aluminum alloy while taking precipitates into account is presented in [33]. Results are provided for strains smaller than 0.1 .

In [34], a physically based model for commercial-purity aluminum for the simulation of equal channel angular pressing (ECAP) is presented. The grain size is taken into account in the microstructure evolution equation in order to account for continuous dynamic recrystallization. ECAP processing takes place at room temperature, which means that the model does not consider the effects of elevated temperatures. The material model was implemented in the finite element code Abaqus/Explicit.

Another material model that takes into account microstructure for the continuous dynamic recrystallization of an $\mathrm{Al} 5052$ aluminum alloy is presented in [35]. The model is validated for strains up to 1.2, strain rates up to $1 \mathrm{~s}^{-1}$ and temperatures of $450{ }^{\circ} \mathrm{C}$ with values taken from the literature. However, it is not implemented into a finite element or SPH code.

A model that predicts the precipitate evolution during FSW for an Al 7449 aluminum alloy is presented in [36]. The model needs input in the form of time-temperature profiles obtained from continuum mechanics simulations. Based on this information, the nucleation and growth of precipitates are calculated. A comparison of the results of the model with in-situ small angle X-ray scattering measurements is presented in [37].

More detailed information on the evolution of the microstructure of materials can be gained through other approaches like mean field theory, as presented in [38] for the simulation of discontinuous dynamic recrystallization in copper; or atomistic simulations, as presented in [39] for the simulation of precipitation in copper-alloyed alpha-iron. These models do not however provide a description of the yield stress for macroscopic simulations but aim at achieving greater understanding of precipitations and the complex interactions of materials under various loading conditions.

\section{Material modeling}

The yield strength of a metal with a facecentered cubic (FCC) crystal system like aluminum can be calculated by adding five different contributions

$\sigma_{\mathrm{y}}=\sigma_{0}+\sigma_{\mathrm{d}}+\sigma_{\mathrm{pl}}+\sigma_{\mathrm{sol}}+\sigma_{\text {prec }}$.

The contributions are the yield strength of pure aluminum $\sigma_{0}$, a contribution from the grain size $\sigma_{\mathrm{d}}$, a contribution from work hardening $\sigma_{\mathrm{p}}$, a contribution from solid solution hardening $\sigma_{\text {sol }}$, and a contribution from precipitation hardening $\sigma_{\text {prec }}$. Since the focus of this work is on a 5000 series aluminum alloy, the precipitation aspect can be neglected and the description for the yield stress reduces to

$\sigma_{\mathrm{y}}=\sigma_{0}+\sigma_{\mathrm{d}}+\sigma_{\mathrm{pl}}+\sigma_{\mathrm{sol}}$.

The strength of pure aluminum is assumed to be $10 \mathrm{MPa}$ [30, 32], as noted in Equation (3). The influence of grain size on the strength of the material can be calculated through the Hall-Petch relationship, as shown in Equation (4). Work hardening can be described by the relationship shown in Equation (5) where $\rho$ denotes the dislocation density. The influence of solid solution strengthening can be modeled using $\sigma_{\text {sol }}=\mathrm{k}_{\mathrm{j}} \mathrm{C}_{\mathrm{j}}^{2 / 3}[31,32]$ with a concentration in solid solution $C_{j}$ of an element $j$ and a strengthening constant $\mathrm{k}_{\mathrm{j}}$. As listed in Table 1, the main alloying element of EN AW 5182 is magnesium, yielding Equation (6). In this work, it is assumed that $\mathrm{C}_{\mathrm{Mg}}$ is constant and influences of temperature and strain rate on solid solution strengthening are accounted for with a phenomenological equation for the parameter $\mathrm{k}_{\mathrm{Mg}}$. The material constants in

$\sigma_{0} \approx 10 \mathrm{MPa}$,

$\sigma_{d}=k_{d} / \sqrt{D}$

$\sigma_{\mathrm{pl}}=\operatorname{M\alpha Gb} \sqrt{\rho}$,

$\sigma_{\text {sol }}=\mathrm{k}_{\mathrm{Mg}} \mathrm{C}_{\mathrm{Mg}}^{2 / 3}$

and their values are listed in Table 2 .

The description of yield stress is used in conjunction with isotropic von Mises plasticity in order to be able to deal with multiaxial stress states.

The microstructure is described using an evolution equation as presented in [34]. As evident from

$\frac{\dot{\rho}}{\rho_{0}}=\left(\mathrm{k}_{1} \sqrt{\frac{\rho}{\rho_{0}}}-\mathrm{k}_{2} \frac{\rho}{\rho_{0}}+\mathrm{d}_{3} \frac{\mathrm{D}_{0}}{\mathrm{D}}\right) \dot{\varepsilon}_{\mathrm{pl}}$,

dislocation density and grain size are taken into account. The first term with parameter $\mathrm{k}_{1}$ represents athermal work hardening, while the term with parameter $\mathrm{k}_{2}$ represents dynamic recovery and the third term with parameter $\mathrm{d}_{3}$ represents dynamic recrystallization. The quantity $\dot{\varepsilon}_{\mathrm{pl}}$ is the equivalent plastic strain rate.

\begin{tabular}{|c|c|c|c|c|}
\hline Symbol & Name & Numerical value & Unit & Reference \\
\hline $\mathrm{k}_{\mathrm{d}}$ & Hall-Petch constant & $0.04 \times 10^{-3 / 2}$ & $\mathrm{MPa} \times \mathrm{mm}^{1 / 2}$ & {$[30]$} \\
\hline $\mathrm{M}$ & Taylor factor & 2 & - & {$[30,32]$} \\
\hline$\alpha$ & $\begin{array}{c}\text { Material dependent constant } \\
\text { for forest hardening }\end{array}$ & 0.27 & - & {$[32]$} \\
\hline $\mathrm{G}$ & Shear modulus aluminum & 27000 & $\mathrm{MPa}$ & - \\
\hline $\mathrm{b}$ & Burgers vector & $0.286 \times 10^{-6}$ & $\mathrm{~mm}$ & {$[30,32]$} \\
\hline $\mathrm{C}_{\mathrm{Mg}}$ & Concentration Mg & 4.5 & $\%$ & Assumed based on [6] \\
\hline $\mathrm{D}_{0}$ & Initial grain size & 20 & $\mu \mathrm{m}$ & Own analysis \\
\hline$\rho_{0}$ & Initial dislocation density & $8 \times 10^{3}$ & $\mathrm{~mm}^{-2}$ & {$[34]$} \\
\hline
\end{tabular}

Table 2: Constants of the material model 


\begin{tabular}{|c|c|c|c|c|}
\hline $\mathrm{d}_{3}(-)$ & $\mathrm{C}_{\mathrm{x}}(-)$ & $\mathrm{k}_{\mathrm{x}}(-)$ & $\mathrm{x}_{1}(-)$ & $\mathrm{x}_{2}(-)$ \\
\hline $10^{6}$ & 3 & 0.1 & 0.1667 & -0.0625 \\
\hline
\end{tabular}

Table 3: Chosen parameters

Grain size is described using relation

$\mathrm{D}=\mathrm{D}_{0}-\left(\mathrm{D}_{0}-\mathrm{D}_{\mathrm{f}}\right)\left(1-\exp \left(-\mathrm{k}_{\mathrm{x}} \varepsilon_{\mathrm{pl}}^{\mathrm{c}_{\mathrm{x}}}\right)\right)$

also from [34]. There, $D_{0}$ is the initial grain size, $D_{f}$ is the saturation grain size and $c_{x}$ as well as $\mathrm{k}_{\mathrm{x}}$ are parameters. The initial grain size $\mathrm{D}_{0}$ is determined using a chemically etched microsection of $\mathrm{Al} 5182$ base material. Since the grains in the rolled sheets are stretched, the average value of grain size in rolling direction and perpendicular to it was used. A critical strain, noting the start of the recrystallization process is used in [34] with a value of 0.1. Since the aim of the model is to describe the material behavior at large strains, the critical strain was neglected, i. e., set to zero.

The equations presented so far do not include temperature and strain rate dependent terms. In order to fit material data over a broad range of strain rates and temperatures, phenomenological relationships (Equations (9-11)) have been developed in the scope of this work. The saturation grain size in $\mu \mathrm{m}$ is assumed to behave as follows,

$\mathrm{D}_{\mathrm{f}}=10^{-3} \mathrm{~T}^{\mathrm{x}} \dot{\varepsilon}_{\mathrm{pl}}^{\mathrm{x}_{2}}$,
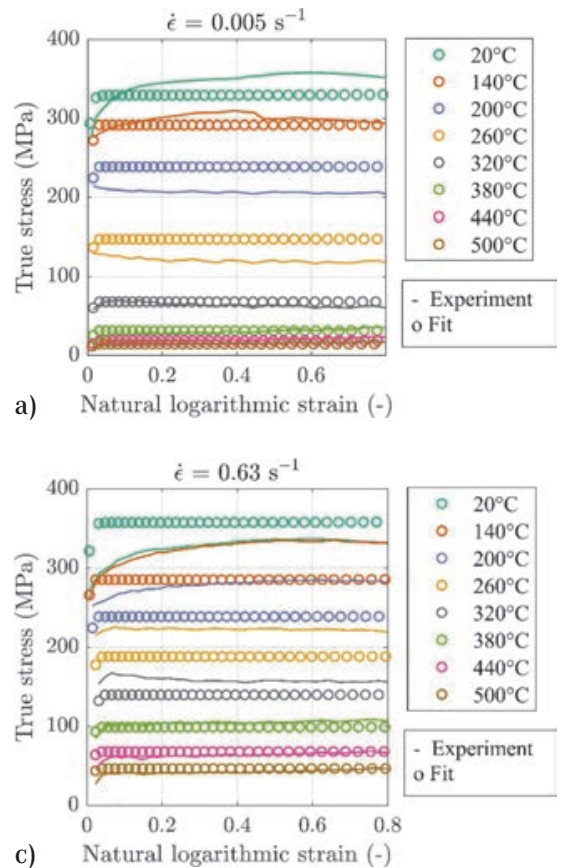

\begin{tabular}{|c|c|c|c|c|c|c|}
\hline $\mathrm{k}_{1}(-)$ & $\mathrm{x}_{3}(-)$ & $\mathrm{x}_{4}(-)$ & $\mathrm{x}_{5}(\mathrm{MPa})$ & $\mathrm{x}_{6}(-)$ & $\mathrm{x}_{7}(-)$ & $\mathrm{x}_{8}(-)$ \\
\hline 689.0 & 92.1 & 0.01 & 131.1 & 0.043 & -0.0083 & -0.186 \\
\hline
\end{tabular}

Table 4: Fitting parameters of the material model

where $T$ is the temperature and $x_{1}$ as well as $\mathrm{X}_{2}$ are parameters. The saturation grain sizes calculated via this equation are in accordance with values found in other works, e.g., [40-42]. The expressions developed for the parameters $\mathrm{k}_{2}$ and $\mathrm{k}_{\mathrm{Mg}}$ have forms

$k_{2}=x_{3} \exp \left(x_{4} T\right)$,

$\mathrm{k}_{\mathrm{Mg}}=\frac{\mathrm{x}_{5} \dot{\varepsilon}_{\mathrm{pl}}^{\mathrm{x}_{6}}}{1+\exp \left(-\mathrm{x}_{7} \dot{\varepsilon}_{\mathrm{pl}}^{\mathrm{x}_{8}}(\mathrm{~T}-250)\right)}$.

An exponential respectively logistic function were found to provide good fits of the experimental stress-strain curves.

In the equations presented, the model does not take kinematic hardening into account. Ways to incorporate kinematic hardening, i. e., the Bauschinger effect, into microstructure-based models of aluminum are for example shown in [32] or [33]. As mentioned in the literature review, the strain ranges taken into account in these works are considerably smaller than the values expected in friction stir welding. In [43], it is shown that the Bauschinger effect in an Al 2024 aluminum alloy decreases the higher the temperatures and strains be-
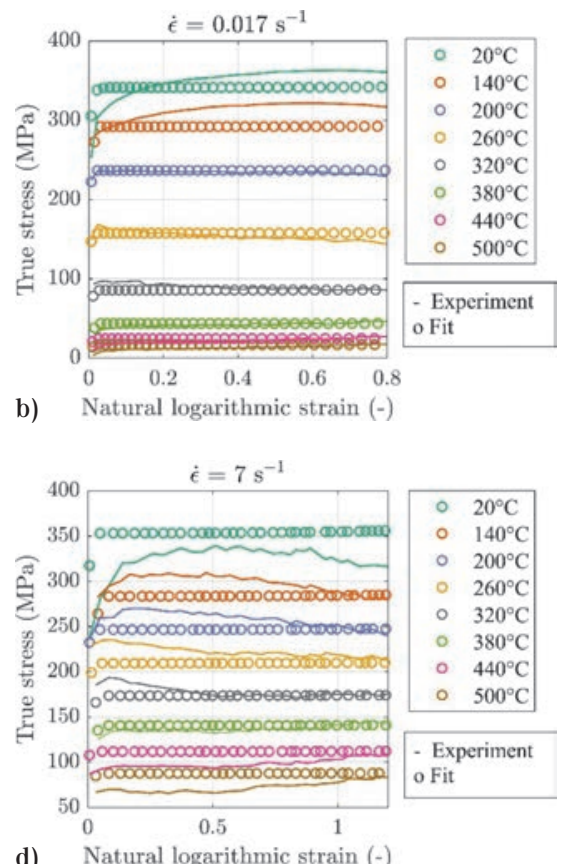

d) Natural logarithmic strain (-) come. Therefore, one should carefully evaluate whether kinematic hardening needs to be considered for FSW process simulations. Additionally, cyclic material testing in the strain regions relevant for friction stir welding is most likely very difficult to realize. For these reasons, only isotropic hardening is considered in this work.

\section{Curve fitting and parameter identification}

The Al 5182 aluminum alloy was characterized using compression tests at various strain rates and temperatures through a Gleeble 2000 thermomechanical testing system. Specimens were tested at four strain rates and eight temperatures. The experimental stress-strain curves were fitted with Matlab using a nonlinear least-squares solver. Using the values listed in Table 3, the fitting coefficients of the material model were calculated as listed in Table 4.

Figure 1 shows the experimental curves as well as the fitted curves calculated using the material model for four strain rates. It is evident that the model delivers reasonable fits especially for higher temperatures. For lower temperatures, not all curves agree well. Considering that it is the aim of the material model to simulate friction stir welding, where higher temperatures are prominent in the process zone, this can be accepted. For a strain rate of $0.63 \mathrm{~s}^{-1}$, the experimental curves for $20^{\circ} \mathrm{C}$ and $140{ }^{\circ} \mathrm{C}$ almost coincide, which is not the case for the other three strain rates. These experimental variations result in problems of matching lower temperatures for this strain rate.

When comparing the various contributions to the yield strength according to Equation (2), the solid solution term $\sigma_{\text {sol }}$ is found to have the greatest influence. This means that the model qualitatively captures the circumstance that the Al 5182 aluminum is alloyed with magnesium to obtain an increase in material strength through solid solution strengthening.

\section{Implementation and model setup}

The material model is implemented for Abaqus/Explicit using the subroutine VUHARD. The evolution equation is a differ-

Figure 1: Comparison of experimental and model data for strain rates $\dot{\varepsilon}=0.005 \mathrm{~s}^{-1}$ a), $\dot{\varepsilon}=0.017 \mathrm{~s}^{-1}$ b), $\dot{\varepsilon}=0.63 s^{-1}$ c) and d) $\dot{\varepsilon}=7 s^{-1}$ 
ential equation. Since no closed form solution exists with the chosen relationships for the coefficients and the grain size, the evolution equation is numerically integrated with respect to the plastic strain $\varepsilon_{\mathrm{pl}}$ using a Euler forward scheme. The equation

$\rho_{\mathrm{i}+1}=\rho_{\mathrm{i}}+\left(\mathrm{k}_{1} \sqrt{\frac{\rho_{\mathrm{i}}}{\rho_{0}}}-\mathrm{k}_{2} \frac{\rho_{\mathrm{i}}}{\rho_{0}}+\mathrm{d}_{3} \frac{\mathrm{D}_{0}}{\mathrm{D}}\right) \rho_{0} \mathrm{~h}$

shows the discretized version of the evolution equation. Compared to Equation (7), the time dependency of $\rho$ and $\varepsilon_{\mathrm{pl}}$ is eliminated.

The grain size is calculated according to Equations (8) and (9). In Equation (12), h is the step size needed for numerical integration. For implementation, the step size chosen is the timestep size calculated and provided by Abaqus for the numerical time integration. After the update of the dislocation density, yield stress can be updated using Equations (2-6). In addition to an expression of yield stress, the derivatives of the yield stress with respect to strain, strain rate, and temperature need to be provided. The derivative with respect to strain was calculated numerically, while the derivatives with respect to strain rate and temperature were calculated analytically.

As a comparison, the material model is also implemented into the Pasimodo [5] environment. Pasimodo is a platform that provides an easy modular way for adoptive implementation, so that new features can be added beyond the existing functionality. In the case of plasticity, it inherits the formulation for the elastic material with its properties and particle interactions, into which the additional influences of plasticity can then be incorporated. The modularity of Pasimodo makes it possible to interchange already existing plasticity laws with newly developed ones. The full Pasimodo description, SPH theory and implementation are intentionally not covered in this paper, since they can be found in other sources. More details on SPH features with regard to solids are introduced in, for example, $[44,45]$ and more about Pasimodo development can be found in [46].

In order to calculate the plastic response of the material, the common radial return scheme [47, 48] is employed. The algorithm presented is adopted directly from the implementation of the Johnson-Cook material model in [44]. It can be divided into the following steps:

- calculate trial yield strength assuming elastic behavior,

- check if yield criterion is satisfied,
- if not - iterate until mapped onto yield surface.

To find the current true yield strength, the Newton-Raphson method [49, 50] is utilized. For that purpose, the residual equation is formed

$\mathrm{R}=\sigma_{\mathrm{y}}\left(\varepsilon_{\mathrm{pl}}(\mathrm{t}+\Delta \mathrm{t})\right)+3 \mathrm{G}\left(\varepsilon_{\mathrm{pl}}(\mathrm{t}+\Delta \mathrm{t})-\right.$

$\left.\varepsilon_{\mathrm{pl}}(\mathrm{t})\right)-\sigma_{\mathrm{vM}}(\mathrm{t}+\Delta \mathrm{t})$,

where $\sigma_{\mathrm{y}}$ is calculated according to Equation $(2), \varepsilon_{p 1}(t+\Delta t)$ and $\varepsilon_{p 1}(t)$ are the plastic equivalent strains from the current and previous time steps, respectively, and $\sigma_{\mathrm{vM}}(\mathrm{t}+\Delta \mathrm{t})$ is an initial guess for the von Mises stress in the current time step. In order to calculate yield stress $\sigma_{y}$, Equations (3-6) and (8-11) are used, while for dislocation density $\rho$ an update formula is used

$\rho(t+\Delta t)=\rho(t)+\Delta t \dot{\rho}$

with the help of evolutionary Equation (7). Here, $\Delta \mathrm{t}$ is the current step size.

To reduce the number of unknowns in Equation (13), the following temporal relationship for the plastic strain rate is applied

$\dot{\varepsilon}_{p l}(\mathrm{t}+\Delta \mathrm{t})=\frac{\varepsilon_{\mathrm{pl}}(\mathrm{t}+\Delta \mathrm{t})-\varepsilon_{\mathrm{pl}}(\mathrm{t})}{\Delta \mathrm{t}}$.

The temperature $\mathrm{T}$ is simply assumed to be constant in Pasimodo during each time step and calculated explicitly after the mechanical interactions. That assumption is acceptable due to the fact that the temperature change per time step is small.

To solve Equation (13) and to apply the Newton Raphson rule, the derivative of Equation (13) with respect to equivalent plastic strain $\varepsilon_{\mathrm{pl}}(\mathrm{t}+\Delta \mathrm{t})$ is taken. This calculation is performed with MATLAB symbolic differentiation due to the complexity of the equation. Further details on the stress-update algorithm are not provided here, as they can be found in full extent in [44].

By running a test case for the algorithm, it can be seen that there are convergence issues which were solved by using the strain rate $\dot{\varepsilon}_{\mathrm{pl}}$ from the previous time step in term $\sigma_{\text {sol }}$, see Equations $(6,11)$, and, therefore, removing its impact on the derivative. Further investigation of this problem will be required and carried out.

In order to test the subroutines implemented and compare the results, a model of the compression test is set up in Abaqus as well as in Pasimodo. The setup of the 3Dmodel is shown in Figure 2. A cylindrical specimen with a diameter of $4 \mathrm{~mm}$ and a

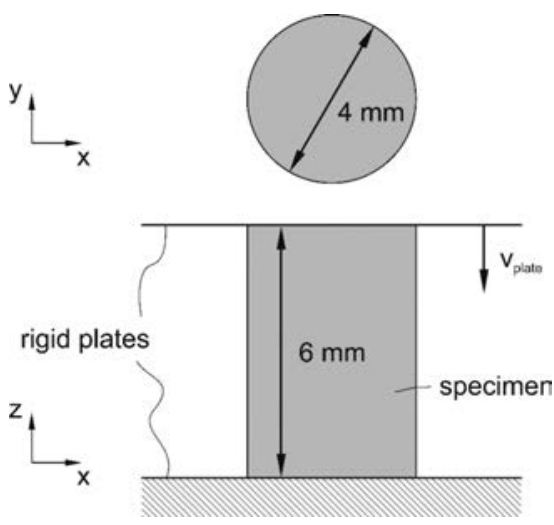

Figure 2: Setup of compression test model

height of $6 \mathrm{~mm}$ is compressed between two rigid plates. While the lower plate is fixed, the upper plate moves at a prescribed velocity. The velocity of the upper plate is chosen according to the strain rates that were tested. As in the experiments, a constant temperature is prescribed for the specimen. Contacts are defined between the specimen and the two plates.

The Coupled Eulerian-Lagrangian method was used to simulate the compression tests with finite elements in Abaqus. This method is able to cope with large deformations and is also used by other researchers to simulate friction stir welding as shown in the literature review. In the case of the compression test, the specimen, i. e., the material, is modeled according to the Eulerian approach while the two plates are modeled as Lagrangian bodies. Theoretical background on the CEL method like governing equations, solution procedures, numerical implementation, or contact formulations can, for example, be found in $[9,51]$ and [52].

As for the SPH setup, the specimen is spatially discretized with particles on a Cartesian grid and the rigid planes are represented by a triangle mesh. A small distance with a value twice that of the particle spacing, see Table 5, is introduced between the specimen and each plane. First, planes are slowly moved towards the body in order to establish the contact. Then, the simulation proceeds in the same manner as in the FEM example, as previously presented. For the interested reader, all the values employed for the SPH-specific simulation are listed in Table 5, while the theoretical background for these can be found in $[44,45]$.

\section{Results}

Figure 3 presents a comparison between experiment and simulation results with Abaqus 


\begin{tabular}{|c|c|c|c|}
\hline Symbol & Name & Numerical value & Unit \\
\hline $\mathrm{L}_{\mathrm{s}}$ & Particle spacing & $1.5 \times 10^{-4}$ & $\mathrm{~m}$ \\
\hline $\mathrm{h}$ & Smoothing length & $2.55 \times 10^{-4}$ & $\mathrm{~m}$ \\
\hline$\rho_{0}$ & Reference density & 2700 & $\mathrm{~kg} \times \mathrm{m}^{-3}$ \\
\hline $\mathrm{m}$ & Mass per particle (including mass scaling) & 0.9112 & $\mathrm{~kg}$ \\
\hline $\mathrm{p}_{0}$ & Reference pressure & 0 & $\mathrm{~Pa}$ \\
\hline$\alpha_{\mathrm{v}}$ & Artificial viscosity linear parameter & 1 & - \\
\hline$\beta_{\mathrm{v}}$ & Artificial viscosity quadratic parameter & 2 & - \\
\hline$\gamma$ & Artificial stress scale factor & 0.18 & - \\
\hline $\mathrm{r}$ & Courant number & 0.2 & - \\
\hline$\xi$ & Stiffness scale factor & $2 \times 10^{7}$ & $\mathrm{~N}$ \\
\hline $\mathrm{v}$ & Friction scale factor & 75 & - \\
\hline $\mathrm{X}$ & Friction gradient factor & 1 & - \\
\hline
\end{tabular}

and Pasimodo for two different strain rates and temperatures. To track the values in the simulations in SPH, a particle at approximately half of the specimen's length was picked, while in FEM, an element at the lower part of the specimen was selected.

Figure 3a shows compression test outputs for strain rate $0.63 \mathrm{~s}^{-1}$ at a temperature of $140{ }^{\circ} \mathrm{C}$. The two simulation results almost coincide, however, the SPH curve has a slightly higher value for equivalent stress. Additionally, there are some oscillations present in the SPH simulation. While the peaks at the beginning of the simulation can be explained by the elastic behavior of the material model and contact establishment, the later ones are due to the strain rate variation in SPH approximation. This can originate from either the nature of $\mathrm{SPH}$, which can be fine-tuned by parameter adjustment, or from convergence issues in the NewtonRaphson algorithm. This issue requires broader investigation for more complex simulation, e. g., FSW. However, in this case, the model produces an accurate enough approximation. The resulting model behaves as predicted by the fit in Figure 1c, producing a flatter curve than in the output produced by the experiment.

Figure $3 \mathrm{~b}$ presents the compression test results for higher strain rate $7 \mathrm{~s}^{-1}$ and temperature $200{ }^{\circ} \mathrm{C}$. In this case, the experiment features a more even stress-strain curve, yielding a better correlation between experiment and fit, see Figure 1d. Consecutively, the simulation results closely follow the experimental output. Similar to the previous example, oscillations are produced in the SPH test case, staying within the range of acceptable deviation, however.

Additionally, a compression test at varying temperature and strain rate of $2.1 \mathrm{~s}^{-1}$ was created and the two implementations, in Pasimodo and Abaqus, were compared. The temporal evolution of equivalent stress and temperature can be seen in Figure 4. Important to notice is that for this test case the SPH approximation does not show oscillations and follows the FEM implementation well in the case of equivalent stress (see Figure 4a). Only close to the end of the simulation time, there is a small deviation between the results, which most likely arises from the temperature difference that can be observed in Figure 4b. The proof for this statement can be seen in Figure 1, where the tests at higher temperatures result in lower levels of stress. The states of the compression test at a simulation time of $0.3 \mathrm{~s}$ for both simulations can be observed in Figure 5. Both specimens feature

Figure 5: Stress distribution over cross-section for FEM (left) and SPH (right) at a time of $0.3 \mathrm{~s}$, the plates are cut for visualization reasons 
even stress distribution over the cross-section with the same value of about $350 \mathrm{MPa}$. Furthermore, the shapes of the profiles are similar, i. e., the radius is wider at the middle of the specimen than in the regions where there is contact with the plates.

To provide an insight into the microstructural evolution, dislocation density was plotted along the timeline of two compression tests at various temperatures. Figure 6 shows two scenarios with isometric temperatures $20^{\circ} \mathrm{C}$ and $200^{\circ} \mathrm{C}$, both with a strain rate of $7 \mathrm{~s}^{-1}$. As expected, plastic deformation at lower temperature leads to more dislocations, therefore providing higher dislocation density. At higher temperatures, the dislocations can move more easily which facilitates the reduction of dislocation density through e.g. polygonization. Furthermore, both FEM and SPH have similar values in the output, but the SPH method results in more rapid growth in the number of dislocations at the beginning of the simulation. The differences in the results between the two discretization methods can possibly be explained by the different evaluation locations.

\section{Conclusions and outlook}

In this work, a physically based material model for the continuum mechanics simulation of the friction stir welding of an Al 5182 aluminum alloy is presented. A microstructure evolution equation taking into account dislocation density and grain size is used in conjunction with a description of yield stress. Phenomenological equations for model parameters are developed to match experimentally obtained stress-strain curves over a wide range of strain rates and temperatures.

The model was implemented for finite element code Abaqus/Explicit as well as for SPH code Pasimodo. In order to test the implementations, a compression test was simulated. The results show that both algorithms provide an accurate approximation of the

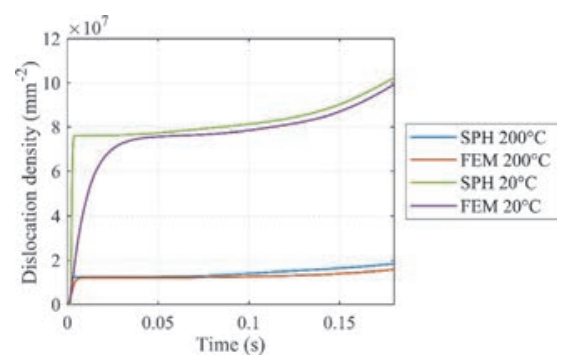

Figure 6: Dislocation density evolution for two different scenarios with isometric temperature $T=20{ }^{\circ} \mathrm{C}$ and $T=200{ }^{\circ} \mathrm{C}$ for $\dot{\varepsilon}=7 \mathrm{~s}^{-1}$ stress-strain relationship for various strain rates and temperatures. However, small oscillations are present in the SPH results for isothermal compression tests. Causes for this problem should be investigated as a simulation with temperature change should provide a smooth output. Since the approximation yields accurate results with small deviation, further analysis is left for the future.

The next step is the simulation of friction stir welding itself using Abaqus as well as Pasimodo with the newly developed material model. In addition to forces and temperature histories, the microstructure of the weld, i. e., grain sizes and dislocation densities, have to be compared with those of the welded specimen. Should the results show strong deviations, modifications in the equations will have to be made. Ideally, the phenomenological equations can be replaced by physically meaningful ones. The model currently does not include effects of precipitation hardening. In order to simulate aluminum alloys of the 2000, 6000 or 7000 series, an extension of the material model is necessary.

The evolution equation, as it is used in this work, does not take into account the possible effects of solid solution strengthening on the dislocation density. The equation could be extended to account for possible interactions between solutes and the dislocation density.

Furthermore, the microstructure evolution equation is integrated using a simple Euler forward integration scheme via the timestep provided by Abaqus. This method works for the simulation of the compression test. Nevertheless, problems may arise in more complex simulation setups. A more sophisticated integration scheme with a step size control for the evolution equation is desirable for the future.

As for SPH implementation, further investigation into the origins of the oscillation as well as temperature evolution should be performed. The SPH implementation provides a good approximation for the cases presented in this study, but more complex scenarios, such as FSW, need to be investigated.

\section{Acknowledgments}

The authors would like to thank the German Research Foundation (Deutsche Forschungsgemeinschaft DFG) for providing funding for the presented research work in the scope of the project "Development and application-oriented validation of a reliable smoothed particle hydrodynamics discre- tization for solids to describe friction stir welding" ("Entwicklung und anwendungsorientierte Validierung einer zuverlässigen Smoothed Particle Hydrodynamics Diskretisierung für Festkörper zur Beschreibung des Rührreibschweißens”) (EB 195/30-1 and SCHM 746/201-1).

\section{References}

1 W. Thomas, E. Nicholas, J. Needham, M. Murch, P. Templesmith, C. Dawes: Great Britain Patent G. B. Patent Application No. 9125978.8 (1991) 2 A. Lakshminarayanan, V. Balasubramanian, K. Elangovan: Effect of welding processes on tensile properties of AA6061 aluminium alloy joints, International Journal of Advanced Manufacturing Technology 40 (2009), No. 3-4, pp. 286-296 DOI:10.1007/s00170-007-1325-0

3 M. Werz, M. Seidenfuß: High-strength friction stir welds for joining aluminum and steel with dissimilar sheet thicknesses, in $11^{\text {th }}$ International Symposium on Friction Stir Welding, Cambridge (2016)

4 J. Monaghan: Smoothed particle hydrodynamics, Reports on Progress in Physics 68 (2005), pp. 1703-1759 DOI:10.1088/0034-4885/68/8/R01

5 https://www.itm.uni-stuttgart.de/en/software/ pasimodo, accessed February 13, 2020

6 DIN EN 573-3: Aluminium and aluminium alloys - Chemical composition and form of wrought products - Part 3: Chemical composition and form of products; German version EN 573-3:2019 DOI:10.31030/3061181

7 H. Schmidt, J. Hattel: A local model for the thermomechanical conditions in friction stir welding, Modelling and Simulation in Materials Science and Engineering 13 (2005), No. 1, pp. 77-93

DOI:10.1088/0965-0393/13/1/006

8 F. Al-Badour, N. Merah, A. Shuaib, A. Bazoune: Coupled Eulerian Lagrangian finite element modeling of friction stir welding processes, Journal of Materials Processing Technology 213 (2013), No. 8, pp. 1433-1439 DOI:10.1016/j.jmatprotec.2013.02.014

9 Z. Zhu, M. Wang, H. Zhang, X. Zhang, T. Yu, Z. Wu: A finite element model to simulate defect formation during friction stir welding, Metals 7 (2017), No. 7, p. 256 DOI: $10.3390 /$ met7070256

10 A. Tongne, C. Desrayaud, M. Jahazi, E. Feulvarch: On material flow in friction stir welded $\mathrm{Al}$ alloys, Journal of Materials Processing Technology 239 (2017), pp. 284-296 DOI:10.1016/j.jmatprotec.2016.08.030

11 Y. Zhu, G. Chen, Q. Chen, G. Zhang, Q. Shi: Simulation of material plastic flow driven by non-uniform friction force during friction stir welding and related defect prediction, Materials and Design 108 (2016), pp. 400-410 DOI:10.1016/j.matdes.2016.06.119

12 W. Pan, D. Li, A. Tartakovsky, S. Ahzi, M. Khraisheh, M. Khaleel: A new smoothed particle hydrodynamics non-Newtonian model for friction stir welding: Process modeling and 
simulation of microstructure evolution in a magnesium alloy, International Journal of Plasticity 48 (2013), pp. 189-204 DOI:10.1016/j.ijplas.2013.02.013

13 K. Fraser, L. St.-Georges, L. Kiss: Meshfree simulation of the entire FSW process on the GPU, $11^{\text {th }}$ International Symposium on Friction stir welding (2016), p. 15

14 X. He, F. Gu, A. Ball: A review of numerical analysis of friction stir welding, Progress in Materials Science 65 (2014), pp. 1-66 DOI:10.1016/j.pmatsci.2014.03.003

15 K. Kuykendall, T. Nelson, C. Sorensen: On the selection of constitutive laws used in modeling friction stir welding, International Journal of Machine Tools and Manufacture 74 (2013), pp. 74-85

DOI:10.1016/j.ijmachtools.2013.07.004

16 M. Nourani, A. S. Milani, S. Yannacopoulos: On the effect of different material constitutive equations in modeling friction stir welding: A review and comparative study on aluminum 6061, International Journal of Advances in Engineering \& Technology 7 (2014), No. 1, pp. $1-20$

17 G. R. Johnson, W. H. Cook: A constitutive model and data for metals subjected to large strains, high strain rates and high temperatures: Proceedings of the $7^{\text {th }}$ International Symposium on Ballistics, Vol. 21 (1983)

18 M. Hoßfeld: A fully coupled thermomechanical 3D model for all phases of friction stir welding, $11^{\text {th }}$ International Symposium on Friction Stir Welding, Cambridge (2016)

19 M. Werz, M. Seidenfuß: Semi-analytical 1D strain-rate based friction stir welding model for predicting material flow, temperature distribution and slip, Mathematical Modelling of Weld Phenomena 11 (2016)

20 K. Fraser: Robust and efficient meshfree solid thermo-mechanics simulation of friction stir welding, Dissertation, Université du Québec à Chicoutimi (2017)

21 F. Humphreys, M. Hatherly: Recrystallization and Related Annealing Phenomena, ${ }^{\text {nd }}$ Ed., Elsevier Ltd, Oxford, UK (2004)

22 M. Grujicic, B. Pandurangan, C. Yen, B. Cheeseman: Modifications in the AA5083 Johnson-Cook material model for use in friction stir welding computational analyses, Journal of Materials Engineering and Performance 21 (2012), No. 11, pp. 2207-2217 DOI:10.1007/s11665-011-0118-7

23 N. Dialami, M. Cervera, M. Chiumenti: Numer ical modelling of microstructure evolution in friction stir welding (FSW), Metals 8 (2018), No. 3, p. 183 DOI:10.3390/met8030183

24 C. Chang, C. Lee, J. Huang: Relationship between grain size and Zener-Holloman parameter during friction stir processing in AZ31 Mg alloys, Scripta Materialia 51 (2004), No. 6, pp. 509-514 DOI:10.1016/j.scriptamat.2004.05.043

25 J. Kim, F. Barlat, C. Kim, K. Chung: Themomechanical and microstructural modeling of friction stir welding of 6111-T4 aluminum alloys, Metals and Materials International 15 (2009), No. 1, pp. 125-132 DOI:10.1080/10408436.2019.1671799
26 U. Kocks: Laws for work-hardening and low-temperature creep, Journal of Engineering Materials and Technology 98 (1976), pp. 76-85 DOI:10.1115/1.3443340

27 Y. Estrin: Dislocation theory based constitutive modelling: Foundations and applications, Journal of Materials Processing Technology 80-81 (1998), pp. 33-39 DOI:10.1016/S0924-0136(98)00208-8

28 L. Lindgren, K. Domkin, S. Hansson: Dislocations, vacancies and solute diffusion in physical based plasticity model for AISI 316L, Mechanics of Materials 40 (2008), No. 11, pp. 907-919 DOI:10.1016/j.mechmat.2008.05.005

29 J. Rodriguez, P. Jonsén, A. Svoboda: Simulation of metal cutting using the particle finite-element method and a physically based plasticity model, Computational Particle Mechanics 4 (2017), No. 1, pp. 35-51 DOI:10.1007/s40571-016-0120-9

30 A. Simar, Y. Bréchet, B. de Meester, A. Denquin, T. Pardoen: Sequential modeling of local precipitation, strength and strain hardening in friction stir welds of an aluminum alloy 6005A- T6, Acta Materialia 55 (2007), No. 18, pp. 6133-6143 DOI:10.1016/j.actamat.2007.07.012

31 A. Simar, Y. Bréchet, B. de Meester, A. Denquin, C. Gallais, T. Pardoen: Integrated modeling of friction stir welding of 6xxx series Al alloys: Process, microstructure and properties, Progress in Materials Science 57 (2012) No. 1 , pp. 95-183 DOI:0.1016/j.pmatsci.2011.05.003

32 D. Bardel, M. Perez, D. Nelias, S. Dancette, P. Chaudet, V. Massardier: Cyclic behaviour of a 6061 aluminium alloy: Coupling precipitation and elastoplastic modelling, Acta Materialia 83 (2014), pp. 256-268 DOI:10.1016/j.actamat.2014.09.034

33 G. Fribourg, Y. Bréchet, A. Deschamps, A. Simar: Microstructure-based modelling of isotropic and kinematic strain hardening in a precipitation-hardened aluminium alloy, Acta Materialia 59 (2011), No. 9, pp. 3621-3635 DOI:10.1016/j.actamat.2011.02.035

34 H. Hallberg, M. Wallin, M. Ristinmaa: Modeling of continuous dynamic recrystallization in commercial-purity aluminum, Materials Science and Engineering A 527 (2010), No. 4-5, pp. 1126-1134 DOI:10.1016/j.msea.2009.09.043

35 G. Maizza, R. Pero, M. Richetta, R. Montanari: Continuous dynamic recrystallization (CDRX) model for aluminum alloys, Journal of Materials Science 53 (2018), No. 6, pp. 4563-4573 DOI:10.1007/s10853-017-1845-4

36 N. Kamp, A. Sullivan, R. Tomasi, J. D. Robson: Modelling of heterogeneous precipitate distribution evolution during friction stir welding process, Acta Materialia 54 (2006), No. 8, pp. 2003-2014 DOI:10.1016/j.actamat.2005.12.024

37 J. dos Santos, P. Staron, T. Fischer, J. Robson, A. Kostka, P. Colegrove, H. Wang, J. Hilgert, L. Bergmann, L. Hütsch, N. Huber, A. Schreyer: Understanding precipitate evolution during friction stir welding of $\mathrm{Al}-\mathrm{Zn}-\mathrm{Mg}-\mathrm{Cu}$ alloy through in-situ measurement coupled with simulation, Acta Materialia 148 (2018), pp. $163-172$

DOI:10.1016/j.actamat.2018.01.020

38 D. Cram, H. Zurob, Y. Brechet, C. Hutchinson: Modelling discontinuous dynamic recrystallization using a physically based model for nucleation, Acta Materialia 57 (2009), No. 17 , pp. 5218-5228

DOI:10.4028/www.scientific.net/ MSF.715-716.492

39 D. Molnar, P. Binkele, S. Hocker, S. Schmauder: Atomistic multiscale simulations on the anisotropic tensile behaviour of copper-alloyed alpha-iron at different states of thermal ageing, Philosophical Magazine 92 (2012), No. 5, pp. 586-607 DOI:10.1080/14786435.2011.630690

40 A. Tronci, R. McKenzie, R. M. Leal, D. M. Rodrigues: Microstructural and mechanical characterisation of 5XXX-H111 friction stir welded tailored blanks, Science and Technology of Welding and Joining 16 (2011), No. 5, pp. 433-439 DOI:10.1179/1362171811Y.0000000012

41 M. Attallah, C. Davis, M. Strangwood: Microstructural development during friction stir welding of work hardenable Al-Mg alloys, The International Conference on Solid-Solid Phase Transformations in Inorganic Materials, USA (2005)

42 L. Fratini, G. Buffa: CDRX modelling in friction stir welding of aluminium alloys, International Journal of Machine Tools and Manufacture 45 (2005), No. 10, pp. 1188-1194 DOI:10.1016/j.ijmachtools.2004.12.001

43 Ö. Karakas, J. Szusta: Bauschinger effect at elevated temperatures in a 2024-T3 aluminum alloy for designing wind turbine components, Materials Testing 59 (2017), No. 9, pp. 735-743 DOI:10.3139/120.111064

44 F. Spreng: Smoothed particle hydrodynamics for ductile solids, Dissertation, Schriften aus dem Institut für Technische und Numerische Mechanik der Universität Stuttgart, Vol. 48, Aachen: Shaker Verlag (2017)

45 E. Shishova, F. Spreng, D. Hamann, P. Eberhard: Tracking of material orientation in updated Lagrangian SPH, Computational Particle Mechanics 6 (2019), No. 3, pp. 449-460 DOI:10.1007/s40571-019-00225-4

46 F. Fleissner: Parallel object oriented simulation with Lagrangian particle methods, Dissertation, Schriften aus dem Institut für Technische und Numerische Mechanik der Universität Stuttgart, Vol. 16, Aachen: Shaker Verlag (2010)

47 M. Wilkins: Calculation of elastic-plastic flow, University of California, Lawrence Radiation Laboratory, Livermore, Technical Report UCRL-7322 (1963)

48 J. Simo, T. Hughes: Computational Inelasticity, Springer, New York, USA, (1998)

49 T. Simpson: Essays on Several Curious and Useful Subjects, in Speculative and Mix'd Mathematicks. Illustrated by a Variety of Examples, J. Nourse, London (1740)

50 F. Cajori: Historical note on the Newton-Raphson method of approximation, The American Mathematical Monthly 18 (1911), No. 2, pp. 29-32 DOI:10.1080/00029890.1911.11997596

51 D. Benson: A mixture theory for contact in multi-material Eulerian formulations, Com- 
puter Methods in Applied Mechanics and Engineering 140 (1997), pp. 59-86 DOI:10.1016/S0045-7825(96)01050-X

52 D. Benson, S. Okazawa: Contact in a multimaterial Eulerian finite element formulation, Computer Methods in Applied Mechanics and Engineering 193 (2004), No. 39-41, pp. $4277-4298$

DOI:10.1016/j.cma.2003.12.061

\section{Bibliography}

DOI $10.3139 / 120.111523$

Materials Testing

62 (2020) 6, pages 603-611

(C) Carl Hanser Verlag GmbH \& Co. KG

ISSN 0025-5300

\section{The authors of this contribution}

Florian Panzer joined the Materials Testing Institute (MPA), University of Stuttgart in 2018 as Research Assistant in the unit "Welding and Joining Technology”. After receiving his Master's degree in Mechanical Engineering from the University of Stuttgart in 2016, he started working as a Research Assistant at the Institute for Materials Testing, Materials Science and Strength of Materials (IMWF) of the University of Stuttgart. The focus of his current work is the joining of dissimilar materials with friction stir welding as well as the experimental and numerical investigation of the dynamics of the friction stir welding process.

Elizaveta Shishova received her Master's degree in Mechanical Engineering from Aalto University in Finland in 2018. Subsequently, she started working as a Research Assistant at the Institute of Engineering and Computational Mechanics (ITM) at the University of Stuttgart in Germany. Her research is aimed at the develop- ment and improvement of smoothed particle hydrodynamics formulation in order to investigate the friction stir welding process.

Dipl.-Ing. Martin Werz joined the Materials Testing Institute (MPA), University of Stuttgart, in 2016 as Head of the Unit, "Welding and Joining Technology". Since 2017, he has been Head of the Department, "Joining Technology and Additive Manufacturing". In 2011, he earned his Master's degree at George Washington University in Washington, DC on the topic "Transportation Safety Engineering". In 2012, he completed his degree (Dipl.-Ing.) in the field of Mechanical Engineering and started to work as an Academic Staff Member at the Institute for Materials Testing, Materials Science and Strength of Materials (IMWF) of the University of Stuttgart. In 2016, he obtained a Degree as Welding Engineer. He regularly participates in ScienceSlams, where scientists present their research work in front of a non-expert audience, and won the German ScienceSlam Championships in 2017 with his Slam title "Friction Stir Welding in the Kitchen" ("Rührreibschweißen in der Küche"). He shows great interest in the correlations between process parameters, material properties and the resulting joint strength. Aside from experimental process studies and optimizations, he is engaged in continuum mechanical modeling and the simulation of the Friction Stir Welding process.

Prof. Dr. Stefan Weihe has been Director of the Materials Testing Institute (MPA), University of Stuttgart, as well as Head and Full Professor at the Institute of Materials Testing, Materials Science and Strength of Materials (IMWF), University of Stuttgart, Germany, since August 2014. He received his Doctorate in Aerospace Engineering at the Institute for Statics and Dynamics of Aerospace Structures, University of Stuttgart, in 1998 and subsequently began working as a Senior
Expert for Chassis Strength, Friction and Wear for Audi AG, Ingolstadt, Germany. From 2002 to 2014, he was a Senior Manager in the field of Strength and Fatigue, Body in White, and Body Concepts and Advanced Engineering in the Development \& Research Department, Division Mercedes-Benz Vans, Daimler AG, Stuttgart, Germany.

Prof. Dr.-Ing. Prof. E.h. Peter Eberhard has been Director of the Institute of Engineering and Computational Mechanics (ITM) at the University of Stuttgart, Germany, since 2002. He is currently Treasurer and Bureau member of IUTAM, the International Union of Theoretical and Applied Mechanics, and previously served in many national and international organizations, for example, as Chairman of the IMSD (International Association for Multibody System Dynamics) and DEKOMECH (German Committee for Mechanics).

Siegfried Schmauder received his Dipl.-Math. degree in Information Technology and his Doctor of Science degree in Materials Science at the University of Stuttgart in 1981 and 1988, respectively. He received an honorary doctorate (Dr.h.c.) from the Universitatea "Ovidius" din Constanta, Romania, in 2017. He started his career as Scientific Assistant at the Max-Planck-Institute for Metals Research in Stuttgart in 1982. From 1991 to 1994, he was the Leader of the group Structural Mechanics at the same institute. Since 1994, he has been a Professor for the Strength of Materials and Materials Technique at the University of Stuttgart. From 2011 to 2014, he was Acting Leader at the Institute for Materials Testing, Materials Science and Strength of Materials. He has coauthored more than 500 papers and five books on micromechanics and applied multiscale materials modeling. 